Acta Crystallographica Section F

Structural Biology

Communications

ISSN 2053-230X

G. Jagadeesan, ${ }^{\mathrm{a}}$ P. Malathy, ${ }^{\mathrm{b}} \mathrm{K}$. Gunasekaran, ${ }^{b}$ S. Harikrishna Etti $^{\mathrm{C}}$ and S. Aravindhan ${ }^{\mathrm{a} *}$

${ }^{a}$ Department of Physics, Presidency College, Chennai 600 005, India, ${ }^{\mathbf{b}} \mathrm{CAS}$ in Crystallography and Biophysics, University of Madras, Chennai 600 025, India, and ${ }^{\mathrm{C} G K M}$ College of Engineering and Technology,

Kamaraj Salai, Chennai 600 063, India

Correspondence e-mail:

aravindhanpresidency@gmail.com

Received 18 June 2014

Accepted 3 September 2014

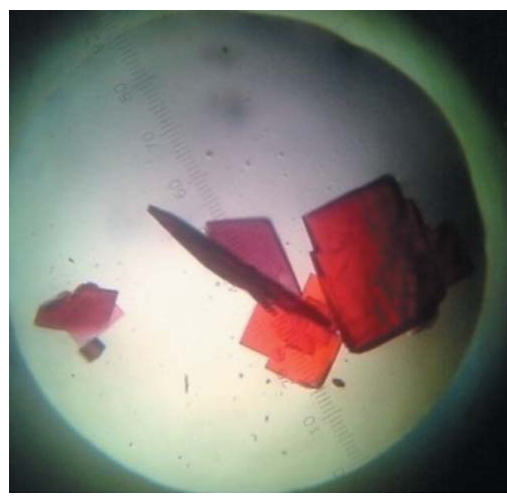

\section{Purification, crystallization, preliminary X-ray diffraction and molecular-replacement studies of great cormorant (Phalacrocorax carbo) haemoglobin}

Haemoglobin is the iron-containing oxygen-transport metalloprotein that is present in the red blood cells of all vertebrates. In recent decades, there has been substantial interest in attempting to understand the structural basis and functional diversity of avian haemoglobins. Towards this end, purification, crystallization, preliminary X-ray diffraction and molecular-replacement studies have been carried out on cormorant (Phalacrocorax carbo) haemoglobin. Crystals were grown by the hanging-drop vapour-diffusion method using PEG $3350, \mathrm{NaCl}$ and glycerol as precipitants. The crystals belonged to the trigonal system $P 3_{1} 21$, with unit-cell parameters $a=b=55.64, c=153.38 \AA$ A $\beta=120.00^{\circ}$; a complete data set was collected to a resolution of $3.5 \AA$. Matthews coefficient analysis indicated that the crystals contained a half-tetramer in the asymmetric unit.

\section{Introduction}

Haemoglobin $(\mathrm{Hb})$, a well studied globular protein, transports oxygen from the heart to different parts of the body. The physiological function of haemoglobin as an oxygen carrier was first demonstrated by Pfluger in 1875. The three-dimensional structure of haemoglobin is held together by hydrogen bonds, salt bridges and weak noncovalent interactions. Haemoglobin is considered to be an allosteric molecule with oxygen acting as a substrate and protons, chloride ion and organic phosphates acting as allosteric effectors. The oxygen affinity of haemoglobin is expressed by the partial pressure $(P)$ of oxygen at which haemoglobin is saturated. In birds, the respiratory system is formed by small air sacs that serve as tidal ventilation for the lungs and have no significant exchange across their cells. The respiratory tract forms a large portion of the total oxygenstorage capacity of the body in birds, whereas in mammals the respiratory-tract oxygen forms a much smaller proportion of the total oxygen storage of the body. Birds are almost unique in their ability to fly, which is a highly energy-consuming form of locomotion. The respiratory system of birds differs from that of mammals by uniquely adapting to very high oxygen consumption during flight. The ability of birds to maintain an efficient oxygen supply to the brain during severe hypoxia is an important adaptation contributing to their exceptional tolerance of extreme altitudes. Compared with mammalian $\mathrm{Hb}$, the presence of hydrophobic residues is increased in avian $\mathrm{Hb}$, which leads to its higher thermal stability and consistent attainment of the tense (T) state (Ajloo et al., 2002). The conservation of hydrophobic domains in avian Hbs might in fact have been required for the stabilization of tertiary structure in order to maintain the function of the protein through a long period of evolution (Perutz, 1983).

The great cormorant (Phalacrocorax carbo), known as the larger cormorant in India, can be observed fishing even deep underwater and can also fly at high altitude. In general, birds that fly at high altitudes have lower $P_{50}$ values; for example, Ruppell's griffon vulture can fly up to $11000 \mathrm{~m}\left(P_{50}=2.1 \mathrm{kPa}\right)$, European black vultures fly at about $4500 \mathrm{~m}\left(P_{50}=2.8 \mathrm{kPa}\right)$ and bar-headed geese can fly up to $8000 \mathrm{~m}\left(P_{50}=3.6 \mathrm{kPa}\right)$ above sea level. Cormorant haemoglobin shares nearly $95 \%$ sequence similarity with those from Ruppell's 
griffon vulture, European black vulture, greylag goose (Liang et al., 2001) and bar-headed goose (Zhang et al., 1996). This shows that the cormorant has retained most of the conserved amino-acid residues (Huber et al., 1988) that help to provide oxygen affinity even at high altitudes. The cormorant can fly at high altitude at a maximum speed of $45.72 \mathrm{~km} \mathrm{~h}^{-1}$ and it can also dive deep into the water to fish even at 30.5-36.6 m. In order to understand the molecular mechanism behind the high oxygen affinity of $\mathrm{Hb}$, we have isolated, purified and crystallized great cormorant haemoglobin and characterized the crystals by means of X-ray diffraction.

\section{Materials and methods}

\subsection{Isolation and purification}

Fresh whole blood from great cormorant was collected, transferred immediately to $0.01 \%$ EDTA to avoid clotting and stored at $4{ }^{\circ} \mathrm{C}$. Red blood cells (RBC) were isolated from blood by centrifugation at $1398 \mathrm{~g}$ for $20 \mathrm{~min}$ at $4^{\circ} \mathrm{C}$ (Neelagandan et al., 2007). Isolated RBC were washed thrice with two volumes of $0.9 \%(w / v)$ saline solution and haemolyzed by the addition of three volumes of ice-cold Millipore water. Subsequent centrifugation at $5590 \mathrm{~g}$ for $1 \mathrm{~h}$ yielded cellfree haemoglobin solution as the supernatant. The isolated protein was extensively dialyzed against distilled water for $24 \mathrm{~h}$ to remove trace salts and the sample was then loaded onto a DEAE-cellulose anion-exchange chromatography column $(15 \times 1.5 \mathrm{~cm})$ equilibrated with $50 \mathrm{~m} M$ sodium phosphate buffer $\mathrm{pH}$ 7. The column was eluted with the same buffer, followed by stepwise elution with various concentrations of sodium chloride $(\mathrm{NaCl})$ solution. A single peak obtained at $0.1 \mathrm{M} \mathrm{NaCl}$ was collected at a rate of $2 \mathrm{ml} \mathrm{min}^{-1}$. A small portion of the sample was used to check for protein content using Bradford assay (Bradford, 1976) and the purity was assessed by native gel electrophoresis (Laemmli, 1970; Fig. 1).

\subsection{Crystallization and X-ray data collection}

Crystals were obtained by the hanging-drop vapour-diffusion method at $18^{\circ} \mathrm{C}$. Polyethylene glycol (PEG) with different molecular weights was initially used to screen the crystallization conditions. It was subsequently found that a combination of PEG 3350 and sodium

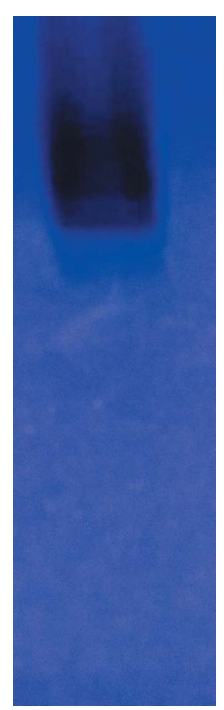

Figure 1

$10 \%$ native PAGE gel stained with Coomassie Blue. Lane 1, cormorant haemolysate $\mathrm{Hb}$. chloride was suitable for obtaining multiple microcrystal clusters. Single crystals were separated from the microcrystal clusters and immediately flash-cooled in liquid nitrogen, but diffracted poorly with streaky spots at very low resolution. Good crystals suitable for X-ray diffraction were grown after $25 \mathrm{~d}$ at $18^{\circ} \mathrm{C}$ using $25 \%$ PEG 3350, $10 \%$ glycerol, $0.5 \mathrm{M} \mathrm{NaCl}, 50 \mathrm{~m} M$ sodium phosphate buffer $\mathrm{pH} 7.5$ equilibrated against $3 \mu \mathrm{l}$ protein solution and $3 \mu \mathrm{l}$ reservoir solution (Fig. 2). The $\mathrm{Hb}$ crystals were mounted in a cryoloop and data were collected at cryotemperature using a MAR345 imaging plate at the Central Leather Research Institute (CLRI), Chennai, India. A total of 108 frames were collected at $18^{\circ} \mathrm{C}$ using a crystal-to-detector distance of $100 \mathrm{~mm}$, an oscillation angle of $1^{\circ}$ and an exposure time of 300 s per image; the crystal diffracted to a maximum resolution of

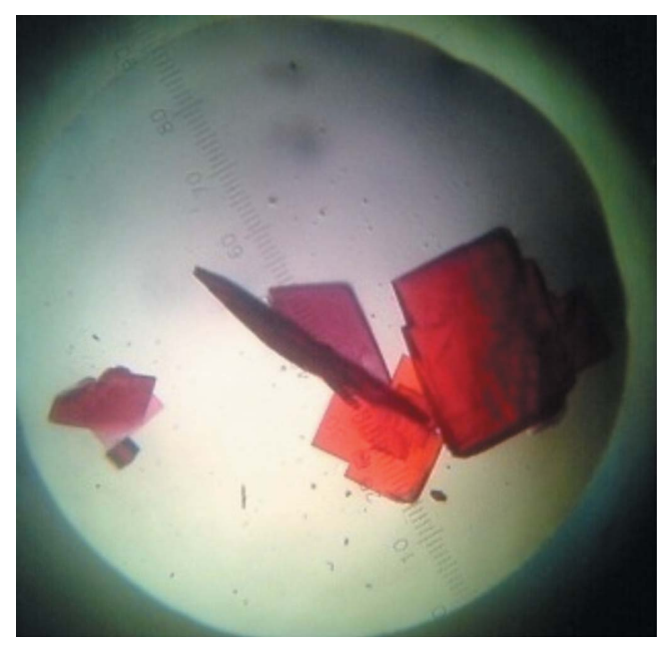

Figure 2

Three-dimensional single crystals of cormorant haemoglobin.

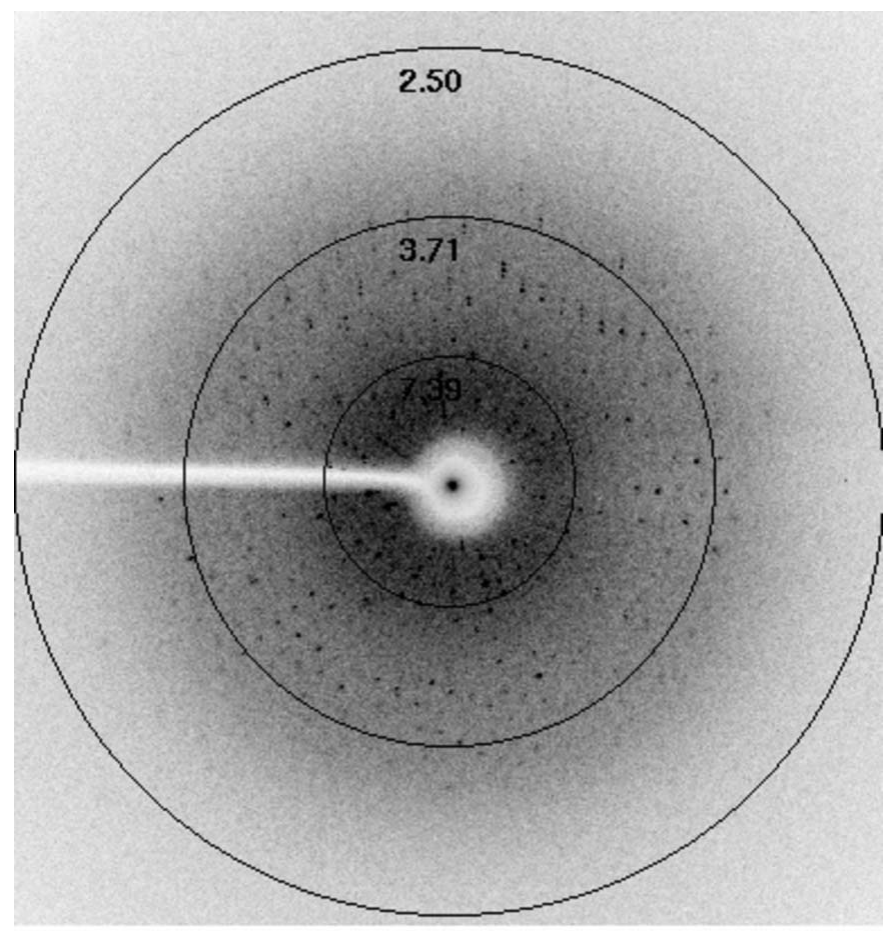

Figure 3

X-ray diffraction pattern of cormorant haemoglobin. 
Table 1

X-ray data-collection and refinement statistics.

\begin{tabular}{|c|c|}
\hline X-ray source & $\mathrm{Cu} K \alpha$ \\
\hline Wavelength $(\AA)$ & 1.5418 \\
\hline Temperature $\left({ }^{\circ} \mathrm{C}\right)$ & -173 \\
\hline Oscillation $\left(^{\circ}\right)$ & 1 \\
\hline Exposure time (s) & 300 \\
\hline Crystal-to-detector distance (mm) & 100 \\
\hline$R_{\text {merge }} \dagger(\%)$ & 17.02 \\
\hline Crystal system & Trigonal \\
\hline Space group & $P 3_{1} 21$ \\
\hline Unit-cell parameters $\left(\AA{ }^{\circ}{ }^{\circ}\right)$ & $a=b=55.64, c=153.38, \gamma=120$ \\
\hline Asymmetric unit content & $\alpha \beta$ dimer \\
\hline Completeness (\%) & 77.2 \\
\hline No. of unique reflections & 2654 \\
\hline$V_{\mathrm{M}}\left(\AA^{3} \mathrm{Da}^{-1}\right)$ & 2.13 \\
\hline Solvent content $(\%)$ & 41.68 \\
\hline Resolution limits (Á) & $13.08-3.5$ \\
\hline No. of reflections in test set & 282 \\
\hline No. of protein atoms & 2217 \\
\hline No. of haem atoms & 86 \\
\hline No. of water molecules & 01 \\
\hline$R_{\text {work }}$ & 0.18 \\
\hline$R_{\text {free }}$ & 0.26 \\
\hline Average $B$ factor $\left(\AA^{2}\right)$ & 9.4 \\
\hline R.m.s.d., bond lengths ( & 0.008 \\
\hline R.m.s.d., bond angles $\left({ }^{\circ}\right)$ & 1.250 \\
\hline \multicolumn{2}{|l|}{ Ramachandran plot statistics (\%) } \\
\hline Most favoured region & 87.2 \\
\hline Additionally allowed region & 12.5 \\
\hline Generously allowed region & 0.4 \\
\hline
\end{tabular}

$\dagger R_{\text {merge }}=\sum_{h k l} \sum_{i}\left|I_{i}(h k l)-\langle I(h k l)\rangle\right| / \sum_{h k l} \sum_{i} I_{i}(h k l)$, where $I_{i}(h k l)$ is the $i$ th measured intensity of reflection $h k l$ and $\langle I(h k l)\rangle$ is the mean intensity.

3.5 A (Fig. 3). Intensity measurements were processed and analyzed using iMosflm (Battye et al., 2011). The data-collection and refinement statistics are summarized in Table 1.

\section{Results and discussion}

Cormorant $\mathrm{Hb}$ was crystallized using a slow nucleation process by adding glycerol to the precipitants along with low-salt buffer conditions. Crystals suitable for X-ray diffraction were obtained after $25 \mathrm{~d}$ and X-ray data were collected to $3.5 \AA$ resolution. Solvent-content analysis indicated that a half-molecule ( $\alpha^{1} \beta^{1}$ subunits) is present in the asymmetric unit with a solvent content of $42 \%$ and a Matthews coefficient (Matthews, 1968) of $2.13 \AA^{3} \mathrm{Da}^{-1}$. Attempts were made to solve the structure by the molecular-replacement method using Phaser (McCoy et al., 2007) as implemented in the CCP4 suite (Winn et al., 2011). The amino-acid sequence of both the $\alpha$ and $\beta$ subunits of cormorant $\mathrm{Hb}$ is highly conserved in both bar-headed and greylag goose Hbs. The coordinates of liganded and unliganded goose Hbs were used as initial search models for molecular replacement. Water molecules were removed from the models to avoid model bias and the best solution was obtained using the oxy form of greylag goose $\mathrm{Hb}$ (Liang et al., 2001). Refinement was carried out in REFMAC (Murshudov et al., 2011) as implemented in the CCP4 suite. A randomly selected $10 \%$ of the total reflections were excluded from refinement in order to use the cross-validation method (Brünger, 1992). Manual model building and structure validation were carried out in Coot (Emsley \& Cowtan, 2004); although the overall resolution of the data set is $3.5 \AA$ only one water molecule was picked up in the $\beta$ haem site based on a simulated-annealing OMIT map. The final $R_{\text {work }}$ and $R_{\text {free }}$ were 0.18 and 0.26 , respectively. Further analysis will be carried out to optimize the crystallization conditions to improve the diffraction quality and obtain higher resolution X-ray data in order to understand the molecular mechanism of cormorant $\mathrm{Hb}$.

The authors thank Dr M. D. Naresh and Dr S. M. Jaimohan of CSIR-CLRI, Chennai for their help during data collection. We thank Professor Dr D. Velmurugan, Head of the Center for Advanced Study in Crystallography and Biophysics, University of Madras, Chennai for allowing us to use the laboratory facility.

\section{References}

Ajloo, D., Moosavi-Movahedi, A. A., Sadeghi, M. \& Gharibi, H. (2002). Acta Biochim. Pol. 49, 459-470.

Battye, T. G. G., Kontogiannis, L., Johnson, O., Powell, H. R. \& Leslie, A. G. W. (2011). Acta Cryst. D67, 271-281.

Bradford, M. M. (1976). Anal. Biochem. 72, 248-254.

Brünger, A. T. (1992). Nature (London), 355, 472-475.

Emsley, P. \& Cowtan, K. (2004). Acta Cryst. D60, 2126-2132.

Huber, K., Braunitzer, G., Schneeganss, D., Kösters, J. \& Grimm, F. (1988). Biol. Chem. Hoppe Seyler, 369, 1251-1258.

Laemmli, U. K. (1970). Nature (London), 227, 680-685.

Liang, Y.-H., Liu, X.-Z., Liu, S.-H. \& Lu, G.-Y. (2001). Acta Cryst. D57, 18501856.

Matthews, B. W. (1968). J. Mol. Biol. 33, 491-497.

McCoy, A. J., Grosse-Kunstleve, R. W., Adams, P. D., Winn, M. D., Storoni, L. C. \& Read, R. J. (2007). J. Appl. Cryst. 40, 658-674.

Murshudov, G. N., Skubák, P., Lebedev, A. A., Pannu, N. S., Steiner, R. A., Nicholls, R. A., Winn, M. D., Long, F. \& Vagin, A. A. (2011). Acta Cryst. D67, 355-367.

Neelagandan, K., Moorthy, P. S., Balasubramanian, M. \& Ponnuswamy, M. N. (2007). Acta Cryst. F63, 887-889.

Perutz, M. F. (1983). Mol. Biol. Evol. 1, 1-28.

Winn, M. D. et al. (2011). Acta Cryst. D67, 235-242.

Zhang, J., Hua, Z., Tame, J. R. H., Lu, G., Zhang, R. \& Gu, X. (1996). J. Mol. Biol. 255, 484-493. 